\title{
DEVELOPMENT OF A DECISION SUPPORT SYSTEM FOR MONITORING, REPORTING AND FORECASTING ECOLOGICAL CONDITIONS OF THE APPALACHIAN TRAIL
}

\author{
Yeqiao Wang ${ }^{* 1}$, Ramakrishna Nemani ${ }^{2}$, Fred Dieffenbach ${ }^{3}$, Kenneth Stolte ${ }^{4}$, Glenn Holcomb ${ }^{5}$, \\ Matt Robinson ${ }^{6}$, C. Casey Reese ${ }^{7}$, Marcia McNiff $^{8}$, Roland Duhaime ${ }^{1}$, Brian Mitchell ${ }^{3}$, \\ Geri Tierney ${ }^{9}$, Peter August ${ }^{1}$, Peter Paton ${ }^{1}$, Charles LaBash ${ }^{1}$
}

1. Department of Natural Resource Science, University of Rhode Island, Kingston, RI 02881, USA

*Corresponding author. E-mail: yqwang@uri.edu

2. NASA Ames Research Center, Moffett Field, CA 94035, USA

3. NPS Appalachian National Scenic Trail/Northeast Temperate Network, Woodstock, VT 05091, USA

4. USDA Forest Service, Southern Research Station, Research Triangle Park, NC 27709, USA

5. Northeast Region, US Geological Survey, Kearneysville, WV 25430, USA

6. Appalachian Trail Conservancy, Harpers Ferry, WV 25425, USA

7. Appalachian National Scenic Trail, National Park Service, Harpers Ferry, WV 25425, USA

8. USGS National Biological Information Infrastructure, Reston, VA 20192, USA

9. College of Environmental Science and Forestry, SUNY, Syracuse, NY 13210, USA

\begin{abstract}
This paper introduces a collaborative multi-agency effort to develop an Appalachian Trail (A.T.) MEGA-Transect Decision Support System (DSS) for monitoring, reporting and forecasting ecological conditions of the A.T. and the surrounding lands. The project is to improve decisionmaking on management of the A.T. by providing a coherent framework for data integration, status report and trend analysis. The A.T. MEGA-Transect DSS is to integrate NASA multi-platform sensor data and modeling through the Terrestrial Observation and Prediction System (TOPS) and in situ measurements from A.T. MEGA-Transect partners to address identified natural resource priorities and improve resource management decisions.
\end{abstract}

Index Terms - Appalachian Trail; TOPS; Integration, Visualization, Modeling

\section{INTRODUCTION}

The purpose of the Appalachian Trail MEGA-Transect Decision Support System (A.T. MEGA-Transect DSS) is to improve the decision-making system that exists between the Appalachian Trail Park Office, the Appalachian Trail Conservancy, the National Park Service and the U.S. Forest Service, and provide a means to convey meaningful information to the American public.
The Appalachian Trail traverses most of the high elevation ridges of the eastern United States, extending about 3,676 kilometers across 14 states, from Springer Mountain in Northern Georgia to Mount Katahdin in central Maine (Figure 1). The A.T. and its corridor intersects 8 National Forests and 6 National Park units; crosses more than 70 State Park, Forest, and Game Management units; and passes through 287 local jurisdictions. A.T.'s gradients in elevation, latitude, and moisture sustain a rich

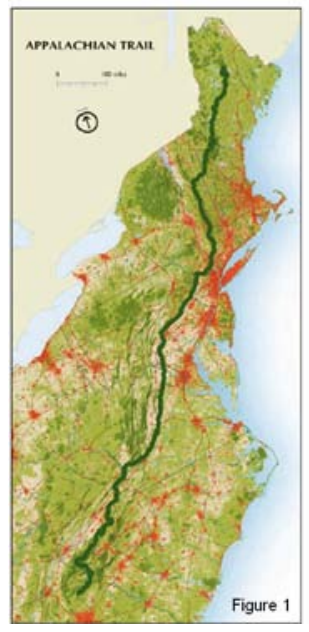
biological assemblage of temperate zone forest species. The A.T. and its surrounding protected lands harbor forests with some of the greatest biological diversity in the U.S., including rare, threatened, and endangered species, and diverse bird and wildlife habitats; and are the headwaters of important water resources of millions of people. The northsouth alignment of the A.T. represents a cross-section MEGA-Transect of the eastern United States forests and alpine areas, and offers a perfect setting for collecting scientifically valid and relevant data on the health of the ecosystems and the species that inhabit them. The high elevation setting of the A.T. and its protected corridor 
provide an ideal barometer for early detection of undesirable changes in the natural resources of the eastern United States, from development encroachment to recreational misuse, acid precipitation, invasions of exotic species, and climate change [1]. The A.T. MEGA-Transect DSS is to integrate NASA multi-platform sensor data products and modeling through the Terrestrial Observation and Prediction System (TOPS) and in situ measurements to address identified natural resource priorities and improve management decisions. The objectives of this project are to:

1. Develop a comprehensive set of seamless indicator data layers consistent with selected A.T. "Vital Signs";

2. Establish a ground monitoring system to complement and integrate TOPS data with in situ observations;

3. Assess historical and current habitat conditions and forecast trends by coupling TOPS data with habitat modeling; and

4. Develop an Internet-based implementation and dissemination system for data visualization, sharing, and management to facilitate collaboration and promote public understanding of the A.T. environment.

\section{RESEARCH DESIGN}

\subsection{Vital Sign Monitoring}

The National Park Service (NPS) Inventory and Monitoring (I\&M) program and A.T. MEGA-Transect partners selected a suite of reliable and representative metrics or Vital Signs for inventory and monitoring long-term ecosystem conditions. Vital signs are defined as a subset of physical, chemical, and biological elements and processes that represent the overall health or condition of different natural resources [2]. Although it may not be possible to match each vital sign with every conceivable NASA data product, several key indicator data layers can be identified and then made available for supporting management decision-making. In this project we focus on three primary vital signs of phenology and climate change; forest health; and, landscape dynamics, and four supplementary vital signs of mountain birds; migratory breeding birds; water resources; and, alpine and high elevation vegetation.

\subsection{TOPS Data and Modeling Products}

The TOPS models allow multi-platform sensor data to be integrated, making it possible to obtain near real-time observations of current (nowcast) ecological conditions as well as predictions for future ecological condition over extensive areas [3]. TOPS data products alone will be a DSS tool that can provide near-real time information on ecological condition over large regions. Integrating NASA EOS data and modeling products that link climate models (e.g., through TOPS) and ecological models (e.g., habitat suitability) with in situ observations, the A.T. MEGA-
Transect DSS is to provide needed geospatial information and improve the effectiveness of decision-making in management of the A.T. lands and for conservation of biodiversity. Multiple sets of temporal data will allow DSS users to build a comprehensive understanding of the current status and trends for the A.T. region in terms of driving factors (e.g., climate, land use/cover) and responsive conditions (e.g., ecosystem productivity, phenological patterns, forest health), and help characterize habitat condition (e.g., landscape configuration and composition, suitability) and primary drivers (e.g., TOPS variables) for simulation and prediction exercises. Some of the baseline TOPS data are listed as follows.

- MODIS Data Products

Landcover Dynamics (MOD12Q2): 2001-2006

Snow Cover 8-days (MOD10A2): 2000 - 2009

Land Cover Type (MOD12Q1): 2001 - 2004

Vegetation Indices (MOD13A2): 2000 - 2009

Leaf Area Index FPAR (MOD15A2): 2000-2009

NDVI (MOD13Q1): 2000 - 2009

Land Surface Temperature (MOD11A2): 2000 - 2009

- $\quad$ GIMMS (Global Inventory Modeling \& Mapping

Studies) NDVI: 1981-2009

- $\quad$ NACP Modeled Carbon Flux, and

- $\quad$ SOGS 1-km Metrological Data from 1976-2008

\subsection{Ground-based Forest Health Monitoring}

In situ forest health monitoring data are being collected in two spatial scales, i.e., the entire A.T. corridor (regional scale) and selected sensitive segments (focused scale) within which more intensive monitoring are directed.

Focused-scale monitoring targets selected segments in midto high-elevation forests. Segments were established by intersecting watersheds of Hydrological Unit Code (HUC10) with A.T. land area. Because A.T. follows ridgelines for a large portion of its length, the watershed lines break the corridor transversely as well as longitudinally. The outcome of the HUC-10 segmentation process was 177 segments ranging in size from approximately 4 hectares to 2185 hectares. Segments less than 425 hectares were eliminated from consideration. Each sampling segment was associated with 10-meter DEM data to determine minimum, maximum and average segment elevation. In the north (i.e., New England region) mid-to-high is defined as $>450$ meters and in the south mid-to-high is defined as $>600$ meters. Average segment elevation proved to be the best selection criteria and was used to select segments. We also considered whether a segment was within a mountain ecoregion as defined by the Bailey Ecoregion system used by the U.S. Forest Service. Plot-based sampling follows the Long-term Forest Monitoring Protocol developed by the Northeast Temperate Network of the NPS I\&M program [4]. Actual sampling locations were set by randomly placing points using the Generalized Random Tessellation Stratified 
(GRTS) methodology. A single GRTS point was assigned to each watershed segment. From the list of segments that met the above criteria, 10 primary and 2 supplementary segments meeting above criteria were selected using the randomly assigned GRTS point ID.

The point selection process created a point file that contains 800,000 randomly distributed points in an area that contains the A.T. corridor plus a 3.2-km buffer. Of the 800,000 points, approximately 47,000 are within the existing corridor, yielding an average density of approximately 200 points per HUC-10 segment. Any point closer than 15-meters from the corridor boundary was excluded, which ensured that no part of the forest monitoring plot would extend onto lands not owned by the A.T., thereby preventing a situation where monitoring would occur on private lands (Figure 2).

Figure 2. The HUC-10 watersheds intersect the A.T. and examples of selected segments and plot locations in Vermont.
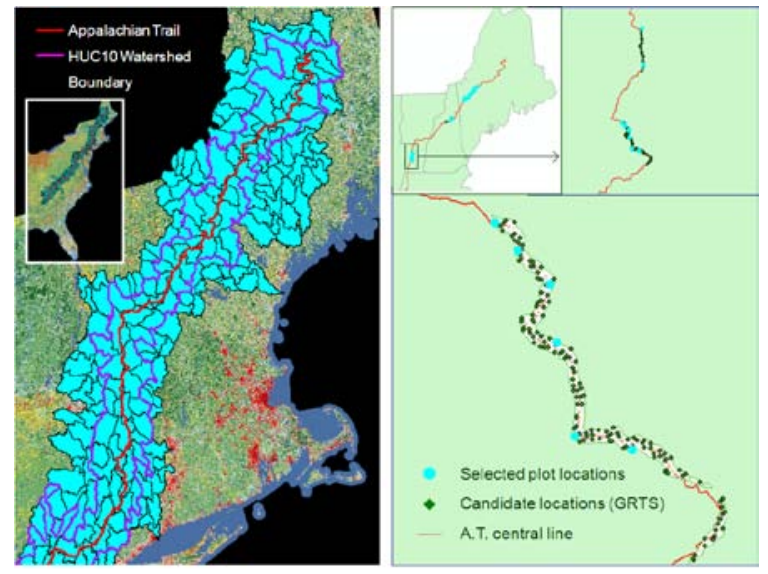

The regional (or landscape) scale field data collection is based on current FIA sampling and plot protocols. It is a probabilistic system (random start and systematic-

distribution) with a FIA Phase 3 plot every 40 miles. This system of long-term biological monitoring plots is centered on the Trail that provides a a consistent sample of the trail and adjacent 288 feet of the corridor. The indicators measured will address many of the NPS Vital Signs and other concerns of the USFS. The data from these plots can be expanded to larger scales and linked with the NASA TOPS data.

Figure 3.

View of AT-FIA plots on AT where it passes through parts of the Jefferson National Forests in the Southern Appalachians. The city of Roanoke VA is located near the trail.

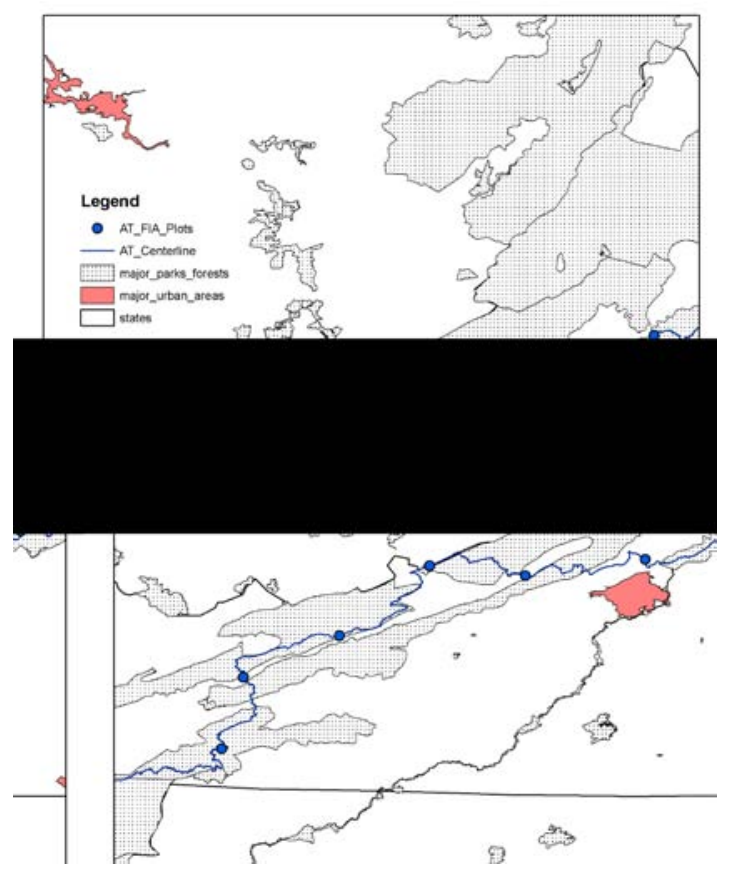


Both sampling designs offered the possibility of incorporating existing data from regional FIA system into the analyses of forest conditions in the adjacent A.T. land.

\subsection{Habitat Monitoring and Modeling}

A variety of scientific research has been devoted to study habitat suitability and conditions [5, 6, 7]. Fearer et al. [8] developed a method for integrating breeding bird survey (BBS) and FIA databases with calculated landscape structure variables from NLCD data to evaluate forest birdhabitat relationship at three hierarchical scales of 100-m, 1 $\mathrm{km}$ and $10 \mathrm{~km}$ radii in the eastern United States. Those studies demonstrate the advantages of data integration, in particular with combination of in situ measurements and satellite-based observations.

Besides the TOPS data and modeling output, other available data such as the LANDFIRE data products [9] are employed. For example, the existing vegetation type (EVT) data developed by the LANDFIRE project represent the current distribution of the terrestrial ecological systems defined as a group of plant community types (associations) that tend to co-occur within landscapes with similar ecological processes, substrates, and/or environmental gradients. The existing vegetation cover (EVC) is generated separately for tree, shrub and herbaceous cover life forms, including percentage tree canopy cover and percentage shrub and herbaceous canopy cover. The existing vegetation height $(\mathrm{EVH})$ is determined by the average height weighted by species cover and based on EVT life-form assignments. Dominant lifeform height of each plot is binned as classes of tree; shrub; and herbaceous vegetation. Through identified data and targeted vital signs, habitat modeling can combine data related to vegetation (e.g., forest type and composition, structure, understory species, tree basal area and distribution, canopy density, and other factors), physical characteristics (e.g., slope, aspect, elevation, etc.), and climate so that the changes of habitat conditions can be studied.

\subsection{Internet-based Implementation and Dissemination}

An Internet-based implementation and dissemination system with commonly adopted software systems is being developed and to provide mapping and visualization services for decision support needs. The system incorporates TOPS to provide users the ability to receive, summarize, analyze, visualize, and identify change and anomalies and forecast trends; integrate directly with ArcGIS; integrate into habitat models for further analysis; incorporate 3-D visualization and viewshed modeling using 10-m high resolution National Elevation Data (NED).
Viewsheds are often modeled from or to specific points on the landscape to better estimate the visibility from or to an interpretive site. The results of viewshed modeling will offer a better understanding of the A.T. land and interaction with impacting factors through enhanced visualization.

\subsection{System Transition}

The ultimate destination for the database and modeling results of the DSS to reside will be the National Biological Information Infrastructure (NBII), managed by the USGS Biological Informatics Office. This transition will benefit from both the existing infrastructure and administrative capability of the NBII, which is a broad, collaborative program to provide increased access to data and information on the nation's biological resources [10].

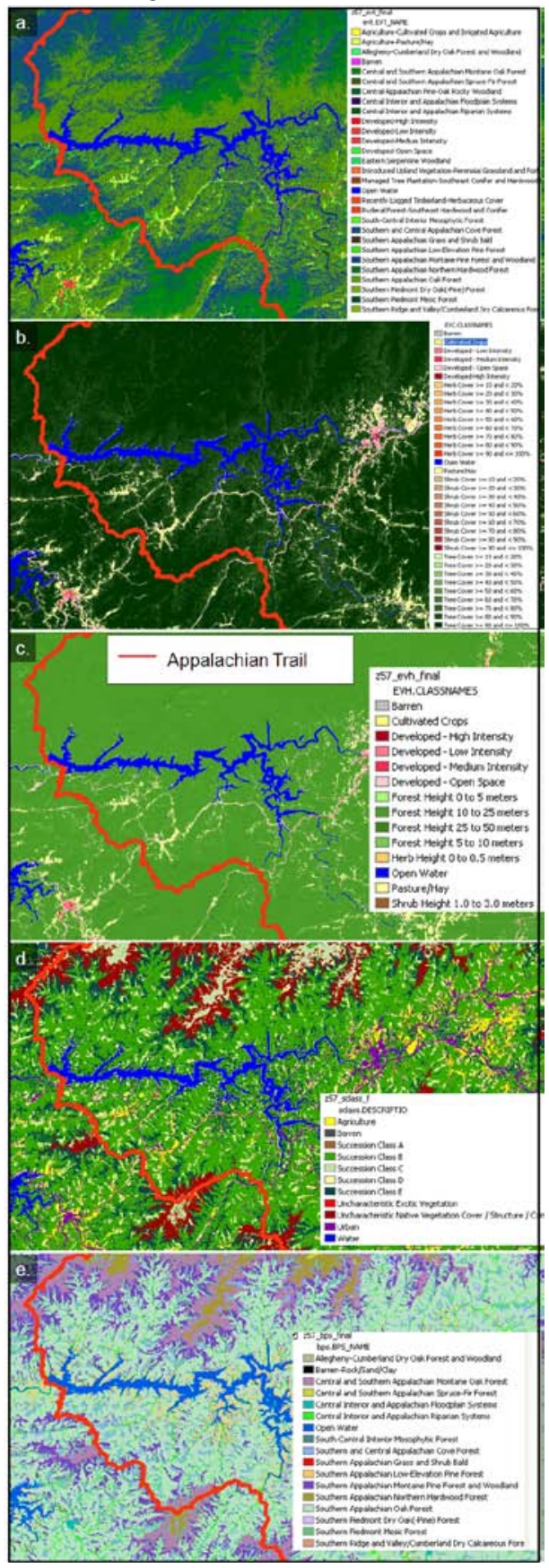


Figure 3. Examples of LANDFIRE data products for existing vegetation (a); existing vegetation cover (b); existing vegetation height (c); succession class (d); and biophysical setting (e) for a section of the A.T. and adjacent lands.

To assure the end user's ability to adopt enhancements to the DSS activities, we held a decision analysis workshop, sponsored by the USGS, which helped identify a set of realistic and useful objectives for the planned DSS, a comprehensive set of real-world decisions that can benefit from better and more timely data, and to identify the most useful information stream and products necessary for input to a practical and useful DSS based on the data, information, and interpretations that the decision makers need.

\section{CONCLUSION REMARKS}

Upon completion, the A.T. MEGA-Transect DSS will allow users to build a comprehensive understanding of the current status and trends for the A.T. region in terms of driving factors and responsive conditions, and help characterize habitat condition and primary drivers for simulation and prediction exercises. The Internet-based visualization and implementation will provide an effective tool for improving decision-making in management of the A.T. lands.

\section{ACKNOWLEDGEMENTS}

The primary funding for this study was provided by NASA (Grant NNX09AV82G). NASA/Rhode Island Space Grant Consortium partially sponsored field data collection (by Grant NNG05GG71H sub-award 00000258).

\section{REFERENCES}

[1] Dufour, Caroline and Elizabeth Crisfield, Eds. The Appalachian Trail MEGA-Transect. Harpers Ferry, WV: Appalachian Trail Conservancy, 2008.

[2] Shriver, G., T. Maniero, K. Schwarzkopf, D. Lambert, F. Dieffenbach, D. Owen, Y. Wang, J. Nugranad-Marzilli, G. Tierney, C. Reese and T. Moore. Appalachian Trail Vital Signs, National Park Service, Northeast Region, Boston, Massachusetts, November 2005.

[3] Nemani, R.R., H. Hashimoto, P. Votava, F. Melton, M. White and W. Wang et al.,. Monitoring and forecasting ecosystem dynamics using the using the Terrestrial Observation and Prediction System (TOPS), Remote Sensing of Environment 113 (7): 1497-1509, 2009.

[4] Tierney, G., B. Mitchell, K. Miller, J. Comiskey, A. Kozlowski, and D. Faber-Langendoen, Long-term forest monitoring protocol: Northeast Temperate Network. Natural Resource Report NPS/NETN/NRR - 2009/117. National Park Service, Fort Collins, Colorado, 2009.

[5] Hinsley S.A., P.E. Bellamy, I. Newton, and T.H. Sparks, Habitat and landscape factors influencing the presence of individual breeding bird species in woodland fragments. $\mathrm{J}$
Avian Biol 26:94-104, 1995.

[6] Dayton, G. and L.A. Fitzgerald, Habitat suitability models for desert anurans. Biological Conservation 132: 40-49, 2006.

[7] Shifley, S.R., F.R. Thompson, W.D. Dijak, M.A. Larson, and J.J. Millspaugh, Simulated effects of forest management alternatives on landscape structure and habitat suitability in the Midwestern United States, Forest Ecology and Management 229: 361-377, 2006.

[8] Fearer T.M., S.P. Risley, D.F. Stauffer, P.D. Keyser, A method for integrating the Breeding Bird Survey and Forest Inventory and Analysis databases to evaluate forest birdhabitat relationships at multiple spatial scales, Forest Ecology and Management, 243(1): 128-143, 2007.

[9] The LANDFIRE, http://www.landfire.gov, June 212010 visit.

[10] National Biological Information Infrastructure, http://www.nbii.gov, June 21, 2010 visit.

Wang, Y., R. Nemani, F. Dieffenbach, K. Stolte, G. Holcomb, M. Robinson, M. McNiff, R. Duhaime, B. Mitchell, G. Tierney, P. August, P. Paton, C. LaBash, 2010. Development of a Decision Support System for Monitoring, Reporting, Forecasting Ecological Conditions of the Appalachian Trail, in Proceedings of IEEE International Geoscience \& Remote Sensing Symposium (IGARSS), 2010, pp. 1-4. 